ARTICLE

https://doi.org/10.1038/s41467-020-17930-x

\title{
Blood substitution therapy rescues the brain of mice from ischemic damage
}

\author{
Xuefang Ren (10) ${ }^{1,2,3,4 凶}$, Heng $\mathrm{Hu}^{1,3,5}$, Imran Farooqi ${ }^{1,6}$ \& James W. Simpkins ${ }^{1,3,7 凶}$
}

Acute stroke causes complex, pathological, and systemic responses that have not been treatable by any single medication. In this study, using a murine transient middle cerebral artery occlusion stroke model, a novel therapeutic strategy is proposed, where blood replacement (BR) robustly reduces infarctions and improves neurological deficits in mice. Our analyses of immune cell subsets suggest that BR therapy substantially decreases neutrophils in blood following a stroke. Electrochemiluminescence detection demonstrates that BR therapy reduces cytokine storm in plasma and ELISA demonstrates reduced levels of matrix metalloproteinase-9 (MMP-9) in the plasma and brains at different time points post-stroke. Further, we have demonstrated that the addition of MMP-9 to the blood diminishes the protective effect of the BR therapy. Our study is the first to show that BR therapy leads to profoundly improved stroke outcomes in mice and that the improved outcomes are mediated via MMP-9. These results offer new insights into the mechanisms of stroke damage.

\footnotetext{
${ }^{1}$ Department of Neuroscience, West Virginia University, Morgantown, West Virginia 26506, USA. ${ }^{2}$ Department of Microbiology, Immunology and Cell Biology, School of Medicine, West Virginia University, Morgantown, West Virginia 26506, USA. ${ }^{3}$ Experimental Stroke Core, Center for Basic and Translational Stroke Research, Rockefeller Neuroscience Institute, West Virginia University, Morgantown, West Virginia 26506, USA. ${ }^{4}$ Present address: Erma Building Room 109, 64 Medical Center Drive, Morgantown, West Virginia 26506-9303, USA. ${ }^{5}$ Present address: 64 Medical Center Drive, Morgantown, West Virginia 26506-9303, USA. 'Present address: EWMS Physical Medicine and Rehabilitation, 721 Fairfax Avenue, 3rd Floor, Norfolk, Virginia 23507-2007, USA. ${ }^{7}$ Present address: Erma Building Room 105, 64 Medical Center Drive, Morgantown, West Virginia 26506-9303, USA. ${ }^{凶}$ email: xuren@hsc.wvu.edu; jwsimpkins@hsc.wvu.edu
} 
A stroke remains a major cause of morbidity and mortality globally ${ }^{1}$. Current treatments for acute stroke include thrombolytic therapy through the administration of tissue plasminogen activator and the surgical removal of the clot. However, these methods have limited time windows. In the clinical field of stroke, the mantra is "time is brain," because infarct evolves every minute following a stroke.

A stroke is more than just a disruption of blood flow to the brain; stroke pathophysiology is a progressive and systemic response to brain injury ${ }^{2}$. Dynamic breaches of the blood-brain barrier (BBB) has been observed in experimental stroke animal models $s^{3,4}$ and stroke patients ${ }^{5}$. Following BBB disruption after ischemic stroke, a pathological and systemic reaction may be initiated. A hyperinflammatory condition, including an increase in inflammatory cells, cytokines, and chemokines in circulating blood has been documented in stroke ${ }^{6}$. Activated neutrophils secret proteinases such as matrix metalloproteinase-9 (MMP-9), which may cause BBB leakage, extracellular matrix degradation, and evolution of cerebral ischemia ${ }^{7}$. MMP-9 also interacts with chemokines $^{8}$ and cytokines ${ }^{9-11}$, causing a further cascade of postischemic cerebral inflammation that leads to degeneration in brain tissue and exacerbates stroke outcomes.

In this study, using a murine transient middle cerebral artery occlusion (tMCAO) stroke model, we present a therapeutic strategy for stroke-a blood replacement (BR) that substitutes stroke mouse blood with whole blood obtained from naive, healthy donor mice. We have demonstrated that the BR performed at $6.5 \sim 7 \mathrm{~h}$ following a stroke robustly reduces infarct volume and improves neurological deficits. Following the treatment, we demonstrate that the BR therapy significantly reduces the cytokine storm in the plasma. In addition, flow cytometry and enzyme-linked immunosorbent assay (ELISA) have demonstrated substantially reduced neutrophils and decreased levels of MMP-9 in the blood and brains of stroke mice, which received whole blood obtained from naive donor mice. Further, addition of MMP-9 in blood diminishes therapeutic effects of the BR therapy. These results reveal a possible therapy of using blood for brain protection from a stroke.

\section{Results}

The BR therapy improves stroke outcomes in post-stroke mice. Using an experimental stroke animal model of tMCAO, we demonstrated that infarction evolves following a 90 min tMCAO and reperfusion (Supplementary Fig. 1). We determined larger infarction from stroke mice at $23 \mathrm{~h}$ compared to $6 \mathrm{~h}$, indicating that the injury evolves over time after removals of filaments in MCAoccluded stroke mice. We have also demonstrated that stroke alters cellular profiles in blood following a $90 \mathrm{~min}$ tMCAO and ischemic reperfusion in mice (Supplementary Fig. 2). We found that absolute cell numbers of neutrophils $\left(\mathrm{Gr}^{+}\right)$, monocytes, $\mathrm{CD} 4^{+}$cells, $\mathrm{CD} 8^{+}$ cells, and NK1.1 ${ }^{+}$cells were significantly increased but $\mathrm{CD} 19^{+} \mathrm{B}$ cells were decreased at $6 \mathrm{~h}$ post stroke compared to controls. The data suggest that blood might play a critical role in the evolution of a stroke and the injured brain may be rescued if a blood-based strategy is used during a critical time window.

To determine the role of blood in stroke, we conducted a dose-response experiment of $\mathrm{BR}$ on stroke outcomes using a murine tMCAO model (Fig. 1a). Before the BR, we recorded global cerebral blood flow $(\mathrm{CBF})$ changes at four time points as follows: prior to $\mathrm{tMCAO}$, at $1 \mathrm{~min}$ post $\mathrm{tMCAO}$, at $5 \mathrm{~min}$ post reperfusion, and prior to the BR in mice using a Laser Speckle Imager. We confirmed that the MCAO reduced $70 \sim 80 \%$ relative CBF (ratio of $\mathrm{CBF}$ in the right MCA territory: $\mathrm{CBF}$ in the left MCA territory) at the post-tMCAO time point and reperfusion fully recovered the relative $\mathrm{CBF}$ at $5 \mathrm{~min}$ post-reperfusion measurements and prior to the BR in all stroke mice; however, no significant differences were detected among randomized groups of mice (Supplementary Fig. 3). Then, we replaced stroke mice blood with different doses of whole blood obtained from naive donor mice at $6.5 \sim 7 \mathrm{~h}$ after ischemia. Although the data demonstrated that 250 and $500 \mu \mathrm{l}$ of the blood robustly reduced stroke infarction in the cortex, striatum, and hemisphere compared to sham control group, $500 \mu \mathrm{l}$ of the blood had a greater protection in brain damage following a stroke (Fig. 1b, c). Interestingly, neurological deficits were significantly improved in the BR groups compared to the control group (Fig. 1d). Furthermore, we performed an Evans blue extravasation assay and demonstrated that 250 and $500 \mu \mathrm{l}$ of blood protected the $\mathrm{BBB}$, as evidenced by less Evans blue extravasation in ischemic hemispheres (Fig. 1e, f). However, the BR therapy did not change physiology parameters in the blood of stroke mice (Supplementary Table 1).

To further confirm the pathological changes in stroke brains, we conducted cresyl violet staining (Fig. 2a) and hematoxylin and eosin (H\&E) staining (Fig. 2b). At high magnification, we observed typical pyknotic neurons or dark neurons in selected cortex and striatum areas in control mice following $90 \mathrm{~min}$ tMCAO at $23 \mathrm{~h}$ post stroke. Interestingly, morphologically intact neurons were broadly seen in similar brain areas of mice with the BR therapy. The degenerating neurons were broadly detectable by terminal deoxynucleotidyl transferase dUTP nick end labeling (TUNEL) staining (Fig. 2d, positive staining in brown) and Fluora-Jade C (Fig. 2d, positive staining in fluorescent green) staining in control mice but only a few in BR-treated mice. The data clearly demonstrated that the BR therapy prevent brain cells from ischemic damage.

Then we ask whether the BR is neuroprotective or just delays the eventual infarct evolution to its final state. We treated stroke mice with the BR therapy and then evaluated outcomes at $72 \mathrm{~h}$ post stroke (Fig. 3). Infarction did not further evolve in BR therapy-treated stroke mice, while matured infarction was observed in control mice by TTC staining (Fig. 3b, c). The BR therapy-treated mice had significantly better functional outcomes than control mice from post-stroke day 1 through day 3 (Fig. 3d). Taken together, these data suggest that BR therapy results in a profound protection in ischemic brains and offers a therapeutic effect for stroke.

We next sought to understand whether blood transfusion alone or blood withdrawal alone protects stroke outcomes. The mice in both blood transfusion alone and blood withdrawal alone groups had large infarction and high mortalities (six of nine mice died in each group within $23 \mathrm{~h}$ of stroke) (Supplementary Fig. 4), suggesting that transfusion of blood and withdrawal of blood are both required for BR therapy for stroke treatment.

To further assess the effects of blood on outcomes in stroke, we transfused $500 \mu \mathrm{l}$ of whole blood obtained from stroke mice, but this cohort of mice had larger infarct volumes and a higher mortality (six of nine recipient stroke mice died within $23 \mathrm{~h}$ of stroke, mortality is $66.7 \%$ ) than the cohort of mice replaced with blood obtained from naive donor mice (0 of six mice died) (Supplementary Fig. 5). Fisher's exact test determined 90\% power of the mortality differences between whole blood obtained from stroke mice and naive donor mice. The data suggest that blood from healthy donors is important when applying BR therapy in stroke.

The BR therapy alters inflammatory responses in the periphery of stroke mice. It is now accepted that inflammation and the immune system are critical in acute stroke damage ${ }^{12,13}$. As shown in Supplementary Fig. 2, stroke significantly changed cellular profiles in the blood of mice following tMCAO. To further 
a

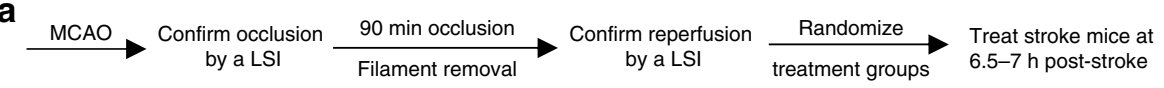
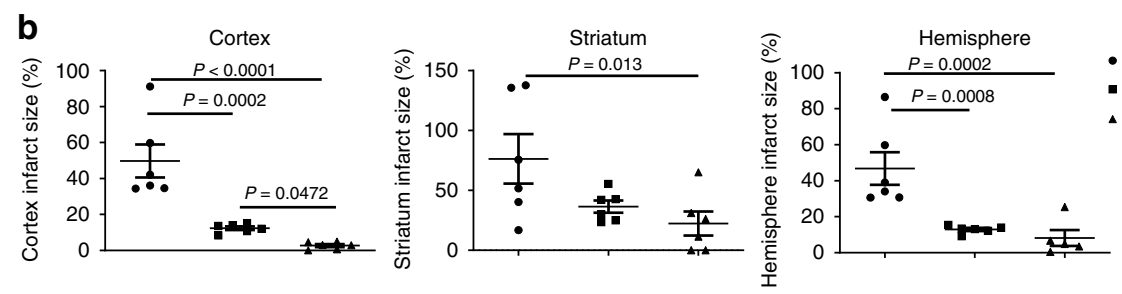

e

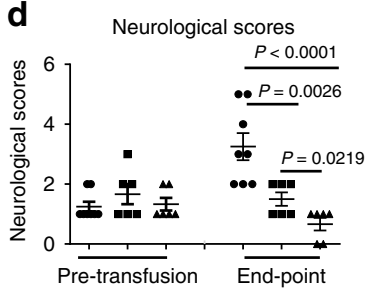

- Control $(n=8)$

- $250 \mu \mathrm{lBR}(n=6)$

- $500 \mu \mathrm{l} \mathrm{BR}(n=6)$

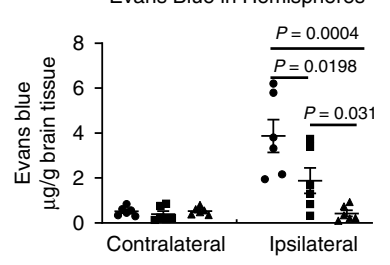

Evaluate stroke outcomes

at 8-h (BBB permeability)

and 23-h (infarction) post-stroke

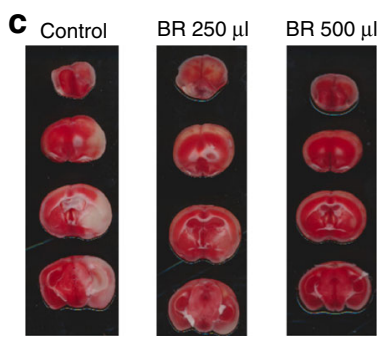

f Control

- Control $(n=6)$

- 250ul BR $(n=6)$

ऽ500ul BR $(n=6)$

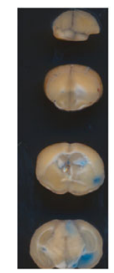

BR $250 \mu \mathrm{l}$

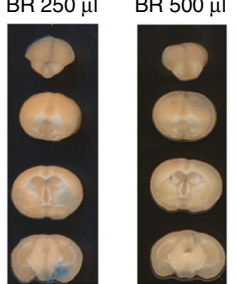

Fig. 1 Blood replacement improves stroke outcomes. a Experimental design. Mice (8 12 months old males) underwent tMCAO for 90 min. The occlusion and reperfusion were confirmed by a laser speckle imager (LSI). Mice were randomized into three groups: sham control, $250 \mu \mathrm{l}$, or $500 \mu \mathrm{l}$ of blood from healthy donors (3 6 months old). Blood was transfused into stroke mice at $6.5 \sim 7 \mathrm{~h}$ post stroke. The same volume of blood was withdrawn from the recipient stroke mice during blood transfusion. Brain infarct volumes were measured at $23 \mathrm{~h}$ after ischemia induction. BBB permeability was evaluated at $1 \mathrm{~h}$ post blood replacement (BR). b BR reduced infarct volume in the cortex, striatum, and total hemisphere dose dependently. Sham control (circles, $n=6$ ), $250 \mu \mathrm{l}$ group (squares, $n=6$ ), or $500 \mu \mathrm{l}$ group (triangles, $n=6$ ) of blood from healthy donors. c Representative triphenyltetrazolium chloride (TTC)stained coronal brain sections used for infarction analyses. $\mathbf{d}$ Neurological deficits were significantly improved in the BR group. Sham control (circles, $n=$ 8), $250 \mu$ l group (squares, $n=6$ ), or $500 \mu$ l group (triangles, $n=6$ ) of blood from healthy donors. e BR reduced Evans blue extravasation in the brain dose dependently. Sham control (circles, $n=6$ ), $250 \mu$ group (squares, $n=6$ ), or $500 \mu$ l group (triangles, $n=6$ ) of blood from healthy donors. $\mathbf{f}$ Representative coronal brain sections showing Evans blue extravasation. Data were presented as means \pm SEM. One-way ANOVA followed by post hoc Fisher's unprotected least-significant difference for multiple comparison tests. Source data are provided as a Source Data file.

a

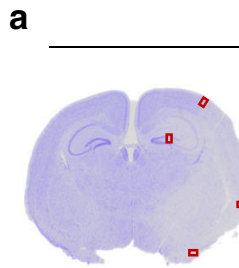

b

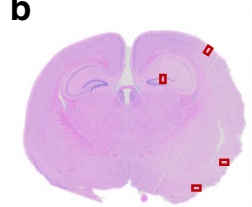

c

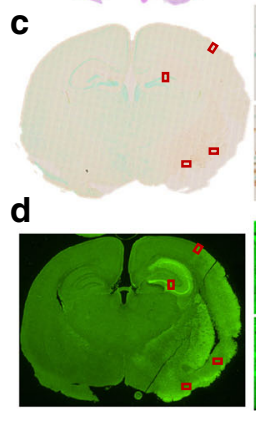

d
Control
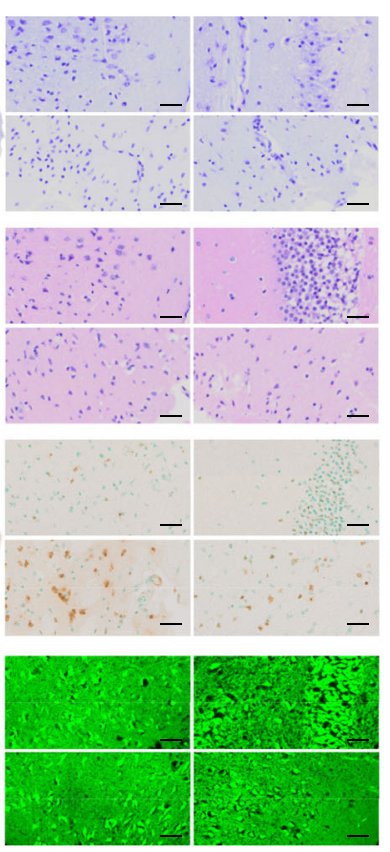

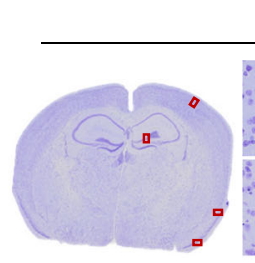

Blood replacement
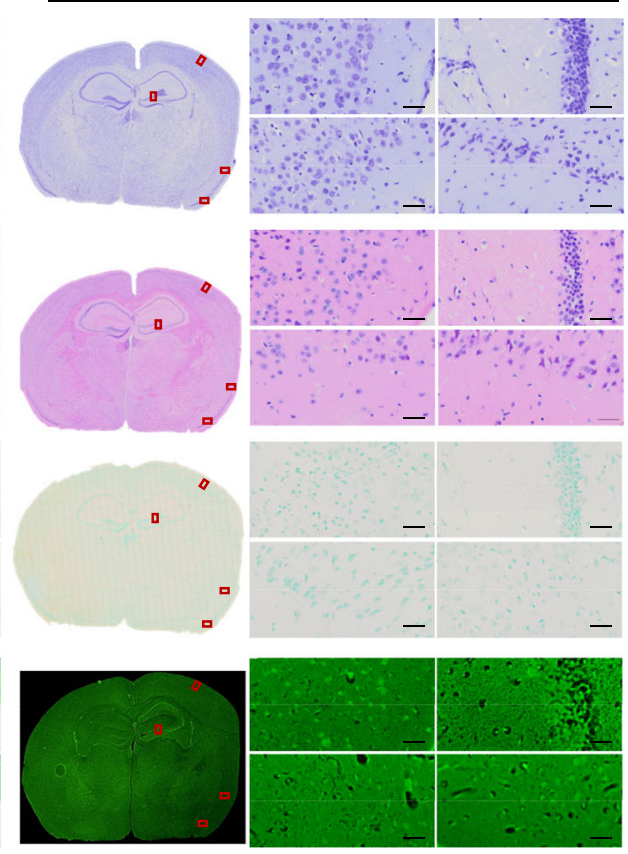

Fig. 2 Blood replacement protects the brain from cell death in stroke mice. Microscopic images of brain tissue taken from stroke mice underwent tMCAO for $90 \mathrm{~min}$ followed by $22.5 \mathrm{~h}$ reperfusion. The blood replacement (BR) group received $500 \mu \mathrm{l}$ of blood from healthy donors (3 6 months old) at 6.5 $7 \mathrm{~h}$ post stroke. a The Cresyl violet staining, b H\&E staining, c TUNEL staining counterstained with Methyl Green, and d Fluoro-Jade C staining were performed on paraffin embedded brain slices. Red rectangles indicate the magnified areas evaluated under $\times 40$ magnification. Both the cortex and striatum were evaluated. Experiments were repeated five times with similar results and images were presentative of one mouse from five mice per group. Scale bars $=20 \mu \mathrm{m}$. 


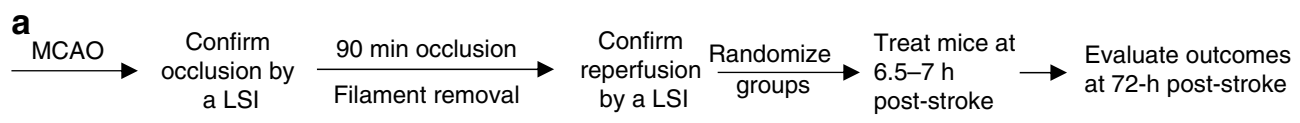

b
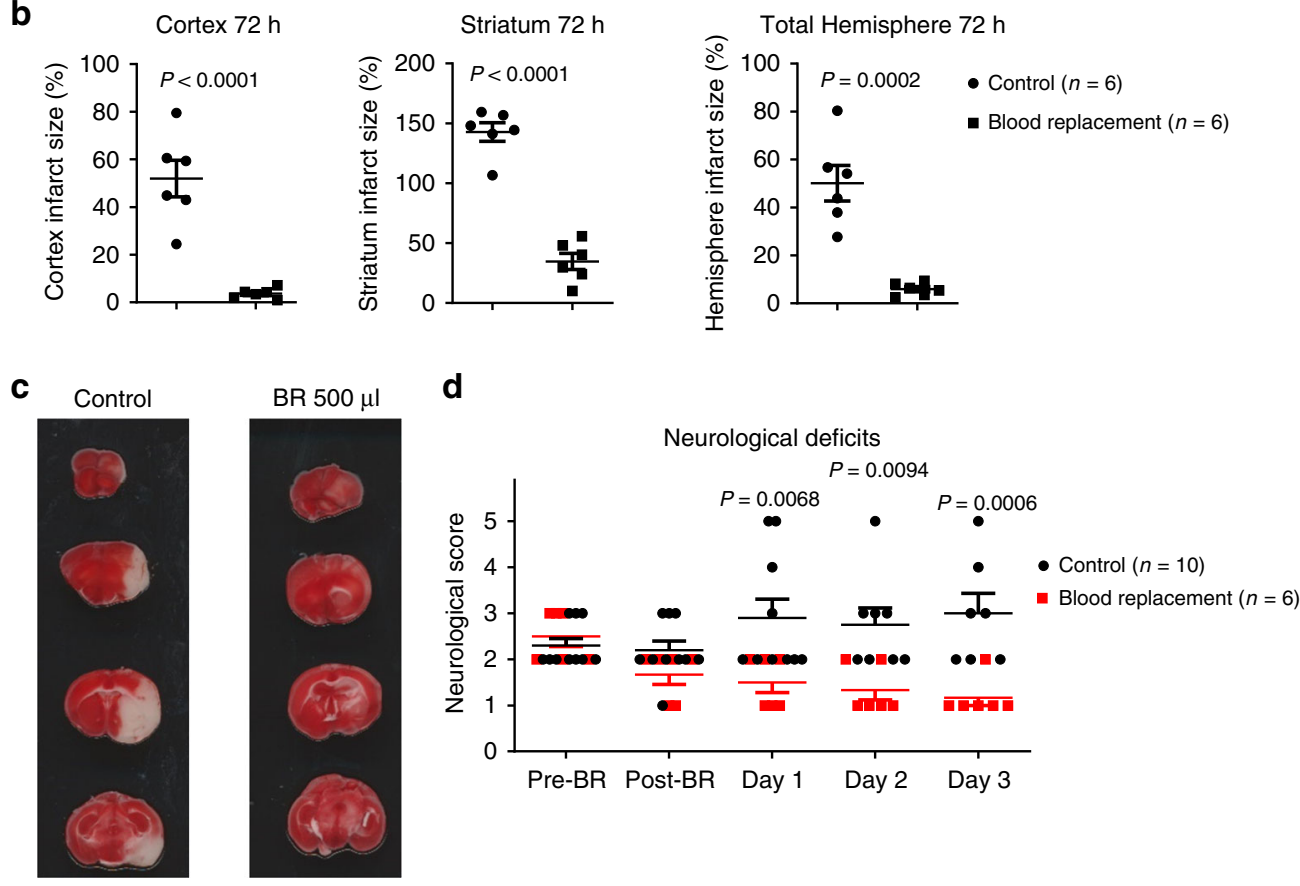

Fig. 3 Blood replacement therapy protects infarct evolution. a Experimental design. Mice underwent $\mathrm{tMCAO}$ for 90 min. The occlusion and reperfusion were confirmed by laser speckle imager (LSI). Mice were randomized into two groups: sham controls and the blood replacement (BR) group receiving $500 \mu \mathrm{l}$ of blood from healthy donors (3 6 months old). Blood was transfused into stroke mice at 6.5 7 h post stroke. The same volume of blood was withdrawn from the recipient stroke mice during blood transfusion. Brain infarct volumes were measured at $72 \mathrm{~h}$ after ischemia induction. $\mathbf{b}$ BR therapy reduced infarct volume in the cortex, striatum, and total hemisphere. Sham controls (circles, $n=6$ ) and the BR group (squares, $n=6$ ). c Representative TTC-stained coronal brain sections used for infarction analyses. $\mathbf{d}$ Neurological deficits were significantly improved in the BR group from day 1 to day 3 . Sham controls (circles, $n=10$ ) and the BR group (squares, $n=6$ ). Data were presented as means $\pm \mathrm{SEM}$; $P$-values were calculated using two-tailed grouped analyses by Student's $t$-test. Source data are provided as a Source Data file.

investigate how BR therapy affects the cellular populations in the blood of stroke mice, we assessed cellular subsets in the blood of recipient stroke mice at three time points-prior to $\mathrm{BR}$, during $\mathrm{BR}$, and at $1 \mathrm{~h}$ post $\mathrm{BR}$. The recipient stroke mice received $500 \mu \mathrm{l}$ of whole blood obtained from either naive donors or stroke mice and additional control group received $500 \mu \mathrm{l}$ of plasma obtained from naive donors (Fig. 4a). In randomized groups, total white blood cell counts were not significantly different prior to the BR (Fig. 4b). Interestingly, whole blood obtained from naive donors resulted in significantly lower total leukocyte numbers and neutrophils during $\mathrm{BR}$ and at $1 \mathrm{~h}$ post $\mathrm{BR}$ in the blood of recipient stroke mice compared to whole blood obtained from stroke mice or plasma obtained from naive donors. There were substantially more total leukocytes and neutrophils but less $\mathrm{CD} 19^{+} \mathrm{B}$ cells in the blood of recipient stroke mice that received whole blood from the stroke mice group and plasma from the naive donor group than the mice that received whole blood from naive donor group. There were no significant changes in monocytes CD4 ${ }^{+}$cells, CD8 + cells, and NK1.1 ${ }^{+}$cells in blood of recipient stroke mice among plasma from naive donor group, whole blood from naive donor group, and whole blood from the stroke mice group (Fig. 4c-1).

In line with the changes of cell numbers in blood of stroke mice, the levels of proinflammatory cytokines and the chemokine, CXCL1, in plasma were also altered (Fig. 5). The data demonstrated that BR therapy significantly reduced the levels of proinflammatory cytokines interleukin (IL)-1 $\beta$, IL-6, TNF- $\alpha$, and the chemokine, CXCL1, at $8 \mathrm{~h}$ post stroke and further reduced IL- 6 , IFN- $\gamma$, and TNF- $\alpha$ at $23 \mathrm{~h}$ post stroke. CXCL1 known as a neutrophil-activating protein is responsible for neutrophil chemotaxis ${ }^{14}$. The significant change of CXCL1 at early stroke suggests that neutrophils might have played an important role in stroke and involved in BR therapy.

The BR therapy alters cerebral leukocyte invasion in stroke mice. Leukocytes are the major effectors of inflammatory damage in stroke brains. Among them, neutrophils and macrophages are early responders to a stroke. To investigate whether BR therapy affects central nervous system (CNS) inflammatory infiltration, we designed a study to analyze leukocyte invasion in the hemispheres of stroke mice (Fig. 6a). The BR therapy significantly reduced total absolute cell numbers in ischemic hemispheres at 8 and $23 \mathrm{~h}$ post stroke (Fig. $6 \mathrm{~b}, \mathrm{c}$ ). To further investigate how BR therapy affects leukocyte composition in the brain after stroke, numbers of infiltrating $\mathrm{Gr} 1^{+}$neutrophils, and $\mathrm{CD} 11 \mathrm{~b}^{+} \mathrm{CD} 45^{\text {high }}$ macrophages, $\mathrm{CD}^{+} \mathrm{T}$ cells and $\mathrm{CD} 19^{+} \mathrm{B}$ cells were assessed by flow cytometry. At both time points, the accumulation of neutrophils and macrophages was significantly less in the affected hemispheres of BR-treated stroke mice compared with control stroke mice (Fig. 6d-i). These data suggest that BR therapy can reduce CNS inflammatory responses to a stroke.

MMP-9 is involved in the BR therapeutic in stroke. MMP-9 is one of proteinases that is expressed by neutrophils and 
a

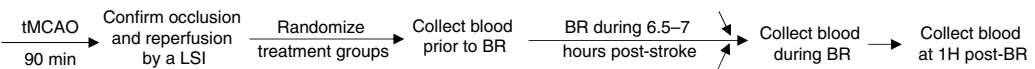
BR: receiving blood from stroke mice (tMCAO, 90min)

C Neutrophils gated on $\mathrm{PI}^{-} \mathrm{CD} 45^{+} \mathrm{CD} 11 \mathrm{~b}^{+} \mathrm{Gr}-1^{+}$live cells
Monocytes gated on $\mathrm{PI}^{-} \mathrm{CD} 45^{+} \mathrm{CD} 11 \mathrm{~b}^{+} \mathrm{Gr}-1^{-}$live cells Monocytes gated on $\mathrm{Pl}^{-} \mathrm{CD} 45$

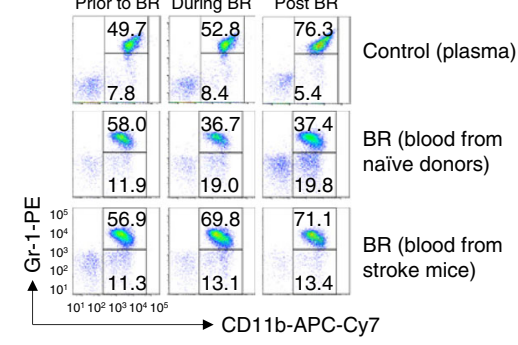

f $\mathrm{CD}^{+}$cells gated on $\mathrm{Pl}^{-} \mathrm{CD} 45^{+} \mathrm{CD} 4^{+}$live cells $\mathrm{CD}^{+}$cells gated on $\mathrm{PI}^{-} \mathrm{CD} 45^{+} \mathrm{CD} 8^{+}$live cells

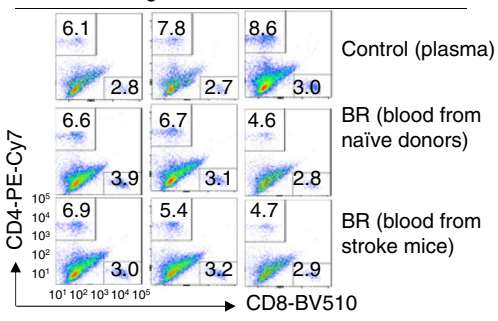

i $\mathrm{CD}_{1}{ }^{+}$cells gated on $\mathrm{PI}^{-} \mathrm{CD} 45^{+} \mathrm{CD} 19^{+}$live cells

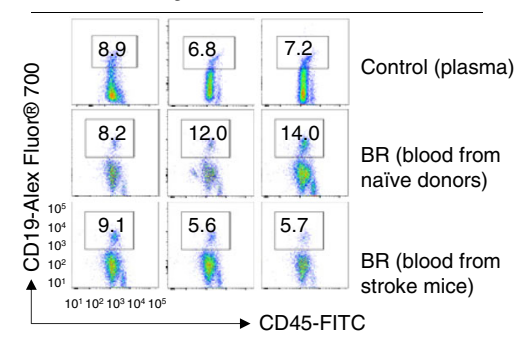

K $\quad \mathrm{NK}_{1.1^{+}}$cells gated on $\mathrm{PI}^{-} \mathrm{CD} 45^{+} \mathrm{NK} 1.1^{+}$live cells

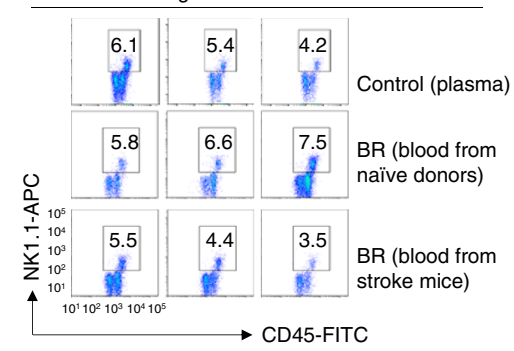

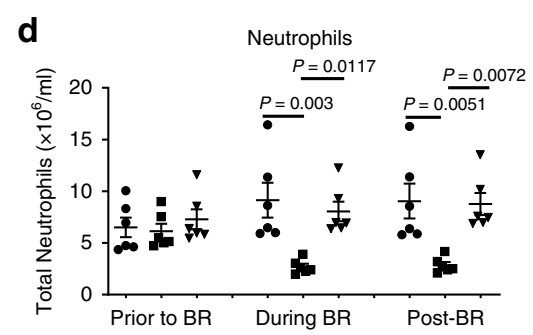
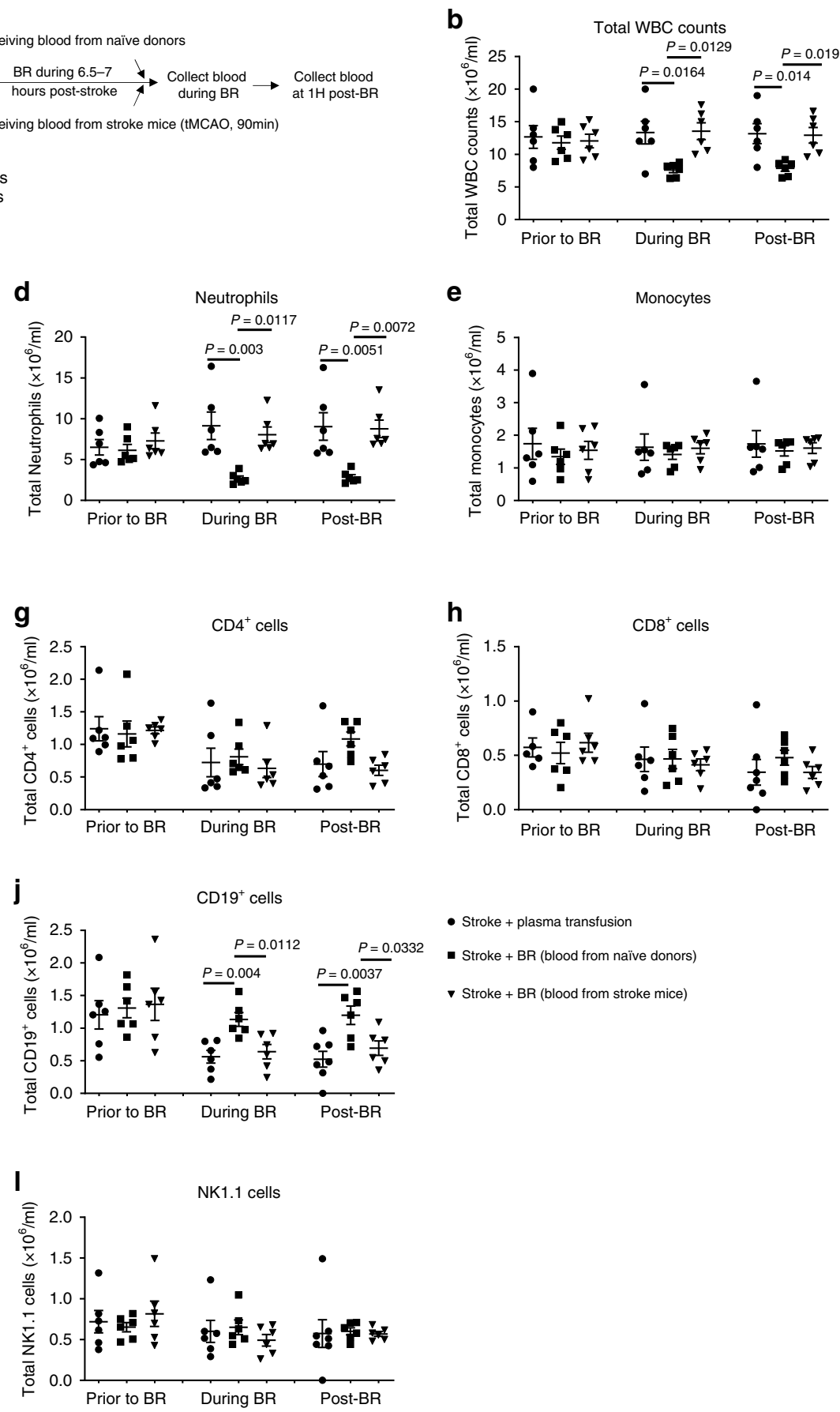

Fig. 4 Blood replacement therapy alters cellular profiles in blood of stroke mice. a Experimental design. Mice ( 8 months old males) underwent $t$ MCAO for $90 \mathrm{~min}$. The occlusion and reperfusion were confirmed by laser speckle imager (LSI). Mice were randomized into three groups: receiving $500 \mu \mathrm{l}$ of plasma (circles, $n=6$ ) from healthy donors, $500 \mu$ l of blood from healthy donors (squares, $n=6$ ), and $500 \mu l$ of blood from stroke mice ( 90 min tMCAO followed by $4.5 \mathrm{~h}$ reperfusion) (triangles, $n=6$ ). Blood was transfused into stroke mice at $6 \sim 8 \mathrm{~h}$ post stroke. The same volume of blood was withdrawn from the recipient stroke mice during blood transfusion. Blood obtained from recipient stroke mice were analyzed at three time points: prior to blood replacement $(B R)$, during $B R$, and at $1 \mathrm{~h}$ post BR. b Total white blood cells were counted. c Representative flow cytometry images for neutrophils gated on propidium iodide $(\mathrm{PI})^{-} \mathrm{CD} 45^{+} \mathrm{CD} 11 \mathrm{~b}^{+} \mathrm{Gr}-1^{+}$populations and monocytes gated on $\mathrm{PI}^{-} \mathrm{CD} 45^{+} \mathrm{CD} 11 b^{+} \mathrm{Gr}-1^{-}$populations. $\mathbf{d}$ Total neutrophil counts. e Total monocyte counts. $\mathbf{f}$ Representative flow cytometry images for $\mathrm{CD} 4^{+}$cells gated on $\mathrm{PI}-\mathrm{CD}^{4} 5^{+} \mathrm{CD} 4^{+}$populations and $\mathrm{CD} 8+{ }^{+}$cells gated on $\mathrm{PI}-\mathrm{CD}^{4} 5^{+}$ CD8 ${ }^{+}$populations. $\mathbf{g}$ Total $\mathrm{CD} 4^{+}$cell counts. $\mathbf{h}$ Total CD8 ${ }^{+}$cell counts. $\mathbf{i}$ Representative flow cytometry images for $\mathrm{CD} 19+\mathrm{B}^{-}$cells gated on $\mathrm{PI}^{-} \mathrm{CD} 45^{+}$ CD19+ populations. j Total CD19+ B-cell counts. k Representative flow cytometry images for $\mathrm{NK}^{+} 1^{+}$cells gated on $\mathrm{PI}{ }^{-} \mathrm{CD} 45^{+} \mathrm{NK} 1.1^{+}$populations. I Total NK1.1+ cell counts. Data were presented as means \pm SEM. One-way ANOVA followed by post hoc Tukey's test was used to determine the significance. Source data are provided as a Source Data file. 

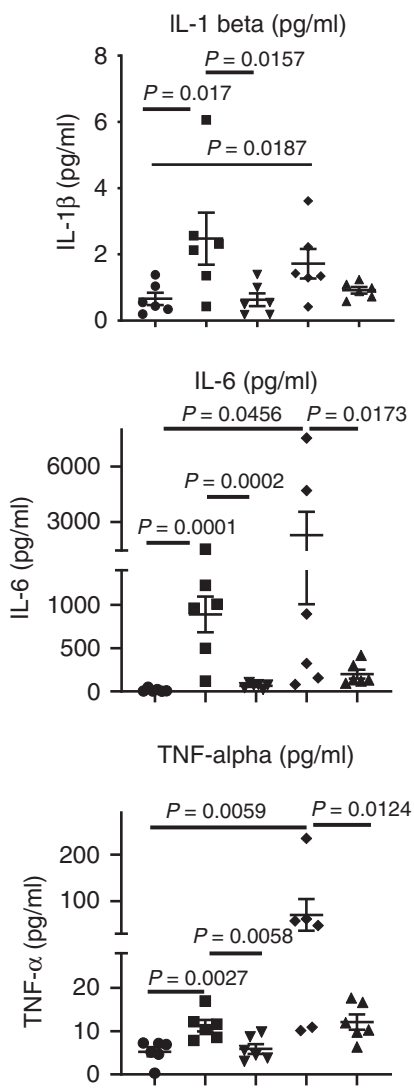
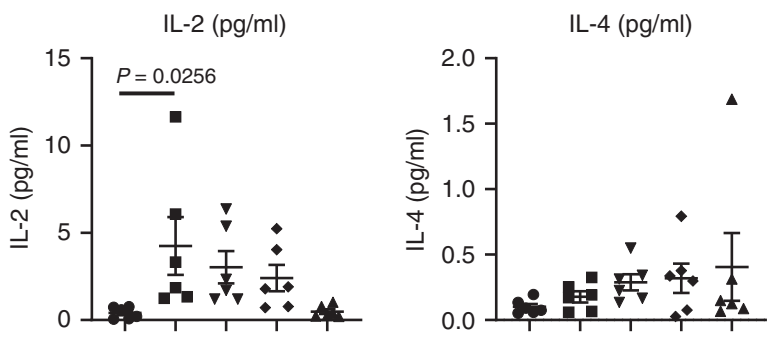

IL-10 (pg/ml)
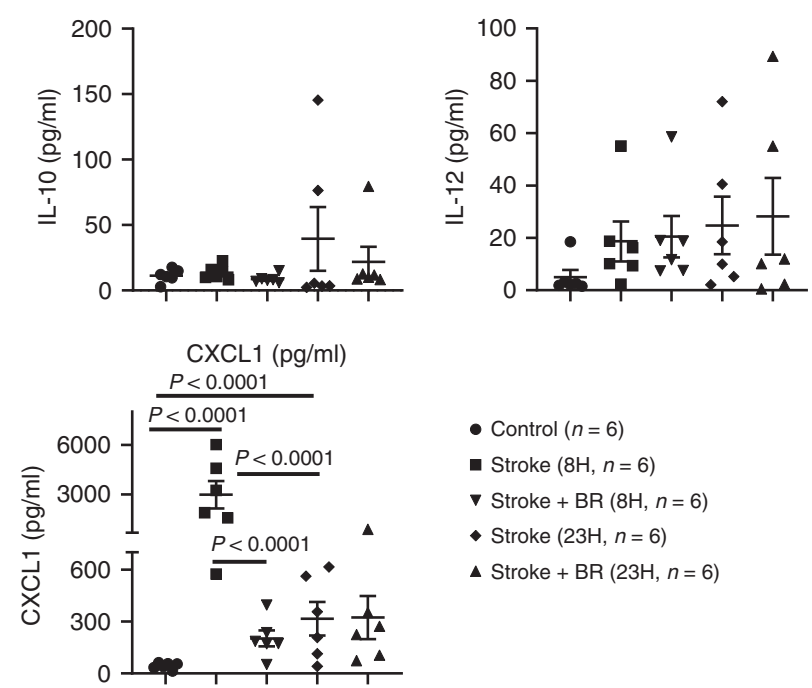

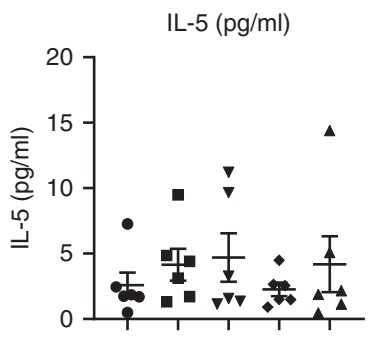

IFN-gamma $(\mathrm{pg} / \mathrm{ml})$

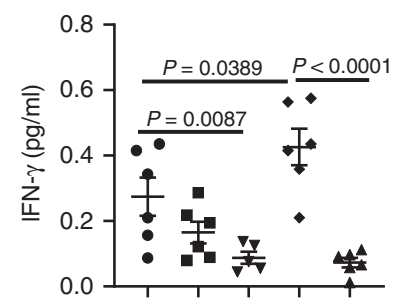

Fig. 5 Blood replacement therapy alters cytokine panel in the plasma of stroke mice. Naive mice (8 12 months old males) serve as a control group (circles, $n=6$ ). Stroke mice (8 12 months old males) underwent tMCAO for $90 \mathrm{~min}$. The occlusion and reperfusion were confirmed by a laser speckle imager. Stroke mice were then randomized into four groups: two groups being killed at 8 (squares, $n=6$ ) and $23 \mathrm{~h}$ (diamonds, $n=6$ ) post stroke; two groups receiving blood replacement (BR) therapy and being killed at 8 (down-pointing triangles, $n=6$ ) and $23 \mathrm{~h}$ (up-pointing triangles, $n=6$ ) post stroke. Then plasma was collected for the analyses of proinflammatory cytokine panel including IL-1 $\beta, I L-2$, IL-4, IL-5, IL-6, IL-10, IL- 12 , IFN- $\gamma$, TNF- $\alpha$, and the chemokine, CXCL1. Data were presented as means \pm SEM. One-way ANOVA followed by post hoc Fisher's unprotected least-significant difference for multiple comparison tests. Source data are provided as a Source Data file.

macrophages/monocytes ${ }^{15}$. MMP-9 is increased in the blood within the first $2-6 \mathrm{~h}$ of stroke in patients, primates, and rodents $^{16-19}$. Given that BR therapy robustly reduced neutrophil counts in the peripheral blood and significantly decreased the infiltration of neutrophils and macrophages/monocytes in ischemic hemispheres, it is important to further investigate how MMP-9 is involved in BR-treated stroke. We designed a study to evaluate the levels of MMP-9 in the plasma and brains following tMCAO with the BR therapy compared to controls (Fig. 7a). We demonstrated increased levels of MMP-9 in the plasma obtained from tMCAO mice compared to controls at both 8 and $23 \mathrm{~h}$ post stroke (Fig. 7b). Interestingly, BR therapy remarkably reduced the levels of MMP-9 in the plasma of recipient stroke mice at both early and late time points (Fig. 7b). However, MMP-2 was not significantly changed between two groups at either time points (Supplementary Fig. 6). We further evaluated the levels of MMP9 in the brains of these mice and demonstrated that BR therapy significantly reduced the levels of MMP-9 in ischemic hemispheres as well (Fig. 7c, d). These data are consistent with neutrophil changes in the periphery and CNS (Figs. 4 and 6), and suggest that the decreased level of MMP-9 could be one of the mechanisms by which the BR therapy improves stroke outcomes.

To further investigate the role of MMP-9 in the BR therapy in stroke, we designed a study of using MMP-9-treated blood compared to vehicle-treated blood for transfusion (Fig. 8a). To compromise the high mortality from 90 tMCAO mice, a $60 \mathrm{~min}$ tMCAO protocol is applied to the study. Interestingly, MMP-9- treated blood significantly exacerbated stroke infarction and worsened neurological deficits, whereas vehicle-treated blood profoundly protected stroke outcomes following $60 \mathrm{~min}$ tMCAO and $22 \mathrm{~h}$ reperfusion (Fig. $8 \mathrm{c}, \mathrm{d}$ ). The data clearly demonstrated that MMP-9 diminished the therapeutic effects of BR in stroke and suggested that a reduced level of MMP-9 could be one of the important mechanisms used by the BR therapy in stroke.

\section{Discussion}

There may be multiple mechanisms occurring in BR. First, brain antigens are released through the $\mathrm{BBB}$ openings and may activate the immune system after stroke. Thus, the removal of blood from stroke mice may reduce the levels of brain antigens in circulating blood and alleviate the activation of immune system by brain antigens. Second, the removal of blood from stroke mice may diminish activated white blood cells and decrease many deleterious signals, such as cytokines, chemokines, proteases, and proteinases in circulating blood after stroke. Third, as observed in patients with thrombotic thrombocytopenic purpura (TTP) disease, where the process of a blood transfusion may supply nutrition factors for the TTP patients ${ }^{20}$, blood may also provide oxygen and many other neuroprotective factors for stroke brains. The mechanisms in the BR therapy for stroke may be more complicated than one factor and it could be a challenge to address all mechanisms here. We here demonstrate the BR therapy as an effective therapeutic strategy for stroke treatment and elucidate MMP-9 involved mechanism in the therapy. 

$\stackrel{\mathrm{tMCAO}}{\longrightarrow} \underset{\text { reperfusion by a LSI }}{\text { Confirm occlusion and }} \underset{\text { Randomize treatment }}{\text { groups }} \rightarrow \frac{\text { BR at 6.5 7 hours }}{\text { post-stroke }} \stackrel{\text { Perfuse animals under anesthesia at }}{\text { 8- and 23-hours post-stroke }} \longrightarrow$ Collect brains for FACS analyses

b

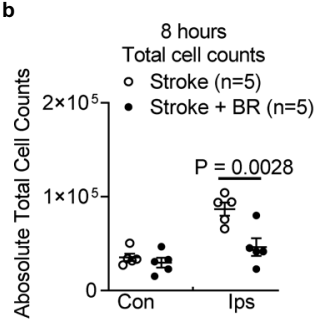

d

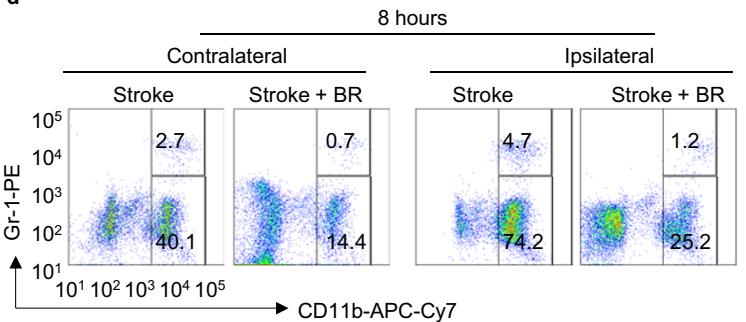

c

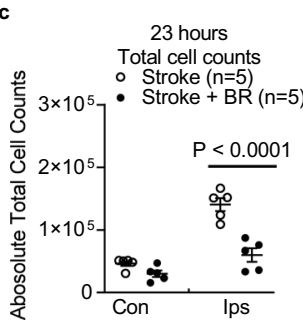

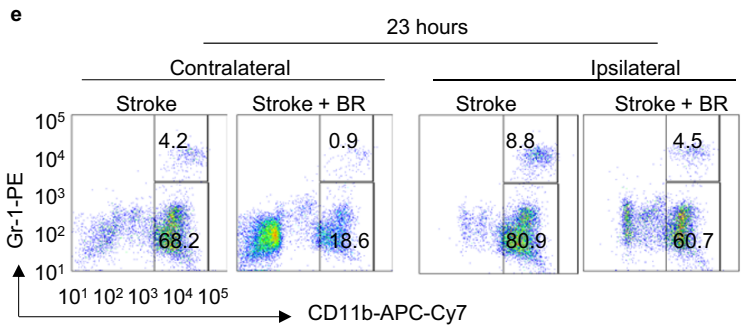
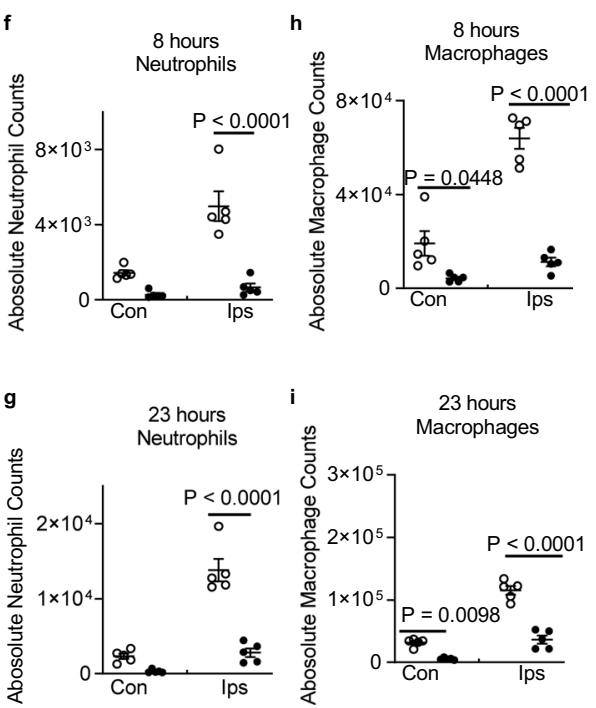

Fig. 6 Blood replacement therapy reduces cell infiltration into brains of stroke mice. a Experimental design. Mice (8 12 months old males) underwent tMCAO for $90 \mathrm{~min}$. The occlusion and reperfusion were confirmed by a laser speckle imager (LSI). Recipient mice were then randomized into two groups: a control group receiving sham surgery (white circles, $n=5$ ) and a blood replacement (BR) group receiving $500 \mu l$ of blood from healthy donors (black circles, $n=5$ ). Blood was replaced into stroke mice at $6.5 \sim 7 \mathrm{~h}$ post stroke. The same volume of blood was withdrawn from the recipient stroke mice during blood transfusion. Brains were perfused and analyzed at 8 and $23 \mathrm{~h}$ after ischemia induction. Blood from naive donors reduced numbers of total inflammatory cells in ischemic hemispheres at $\mathbf{b} 8$ and $\mathbf{c} 23 \mathrm{~h}$ post stroke. Representative flow cytometry images for neutrophils gated on propidium iodide $(\mathrm{PI})^{-} \mathrm{CD} 45^{+} \mathrm{CD} 11 \mathrm{~b}^{+} \mathrm{Gr}-1^{+}$populations and macrophages gated on $\mathrm{PI}^{-} \mathrm{CD} 45^{+} \mathrm{CD} 11 \mathrm{~b}^{+} \mathrm{Gr}-1^{-}$populations in hemispheres at $\mathbf{d} 8$ and $\mathbf{e} 23 \mathrm{~h}$ post stroke. Blood from naive donors reduced numbers of absolute neutrophil counts in ischemic hemispheres at $\mathbf{f} 8$ and $\mathbf{g} 23 \mathrm{~h}$ post stroke. Blood from naive donors reduced numbers of absolute macrophage counts in ischemic hemispheres at $\mathbf{h} 8$ and $\mathbf{i} 23 \mathrm{~h}$ post stroke. Data were presented as means \pm SEM. One-way ANOVA followed by post hoc Tukey's tests. Source data are provided as a Source Data file.

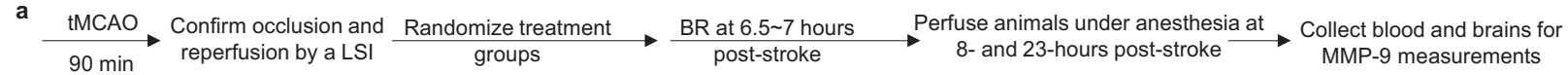

b

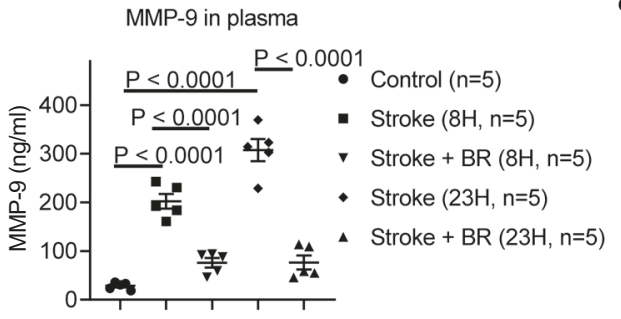

c

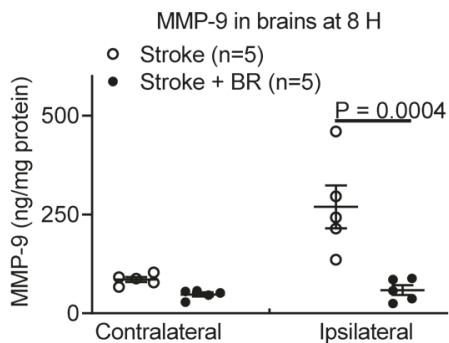

d

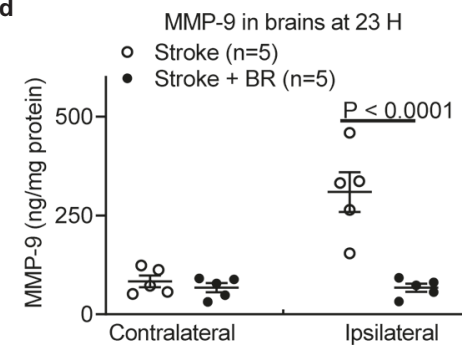

Fig. 7 Blood replacement therapy reduces levels of MMP-9 in the plasma and brains in stroke mice. a Experimental design. Mice (8 12-month-old males) underwent $\mathrm{IMCAO}$ for $90 \mathrm{~min}$. The occlusion and reperfusion were confirmed by a laser speckle imager (LSI). Stroke mice were then randomized into two groups: a stroke only group and a blood replacement (BR) therapy group receiving $500 \mu$ l of blood from healthy donors. Blood was replaced into stroke mice at $6.5 \sim 7 \mathrm{~h}$ post stroke. Brains were perfused and analyzed at 8 and $23 \mathrm{~h}$ after ischemia induction. $\mathbf{b}$ BR therapy reduced levels of MMP-9 in the plasma at 8 and $23 \mathrm{~h}$ post stroke. Control (circles, $n=5$ ), stroke mice analyzed at $8 \mathrm{~h}$ post stroke (squares, $n=5$ ), stroke mice with BR therapy analyzed at $8 \mathrm{~h}$ post stroke (down-pointing triangles, $n=5$ ), stroke mice analyzed at $23 \mathrm{~h}$ post stroke (diamonds, $n=5$ ), stroke mice with BR therapy analyzed at $23 \mathrm{~h}$ post stroke (up-pointing triangles, $n=5$ ). The BR therapy reduced the levels of MMP-9 in ischemic hemispheres at c 8 and $\mathbf{d} 23 \mathrm{~h}$ post stroke. Data were presented as means \pm SEM. One-way ANOVA followed by post hoc Tukey's tests. Stroke mice group (white circles, $n=5$ ); stroke mice with BR therapy group (black circles, $n=5$ ). Source data are provided as a Source Data file.

The average total blood volume of a mouse is about $77 \sim 80 \mathrm{ml}$ $\mathrm{kg}^{-1}\left(0.077 \sim 0.080 \mathrm{ml} \mathrm{gram}^{-1}\right)^{21}$. A mouse weighing $30 \mathrm{~g}$ would therefore have a total blood volume of $\sim(77 \sim 80) \mathrm{ml} \mathrm{kg}^{-1} \times 0.03$ $\mathrm{kg}=2.31 \sim 2.4 \mathrm{ml}$. Transfusion of $500 \mu \mathrm{l}$ of blood is in $<20 \%$ total blood volume. This volume is translatable to human for blood transfusion.
We have investigated the role of separated blood components by the BR treatment in stroke. We conducted a study by testing the effects of transfusion up to $500 \mu \mathrm{l}$ of plasma while withdrawing the same amount of blood from stroke mice. It has been demonstrated that plasma from young mice ameliorates pathology and cognition in a mouse model for Alzheimer's disease ${ }^{22}$. 
a

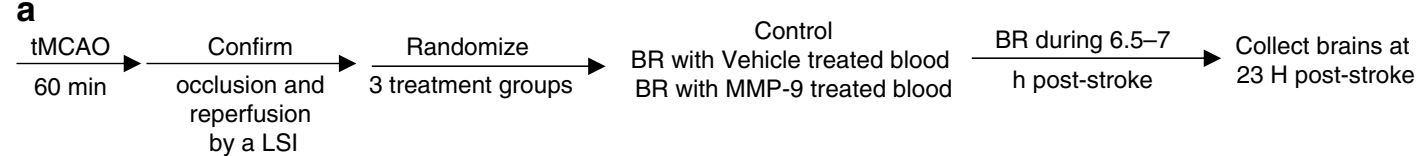

b
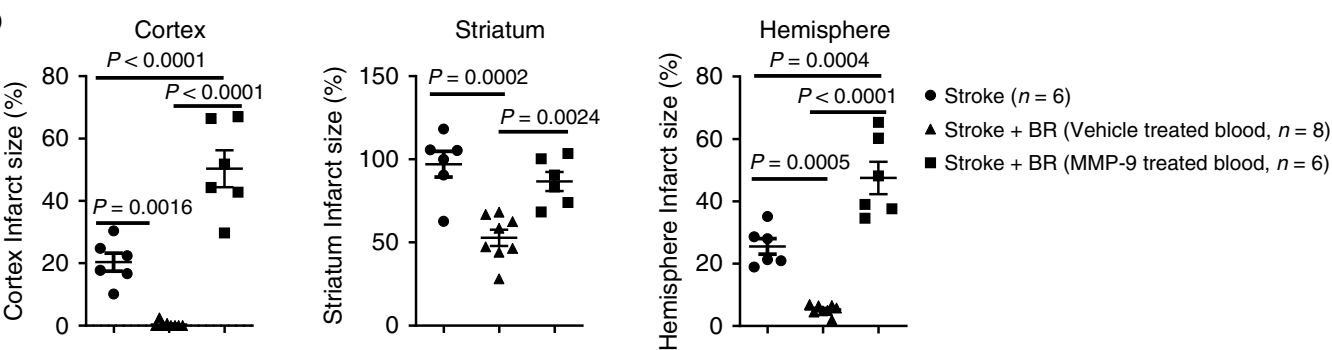

C

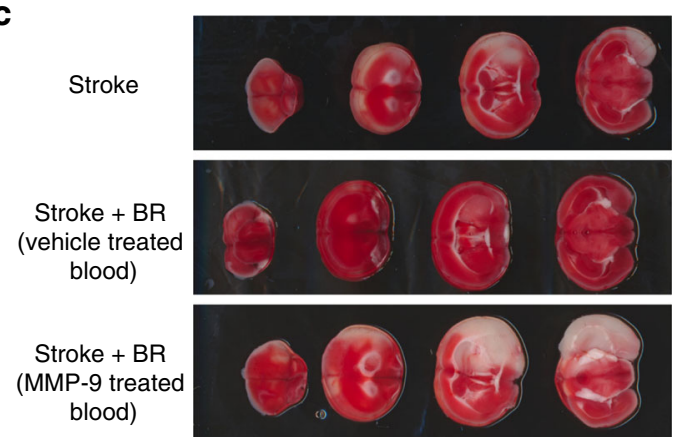

d

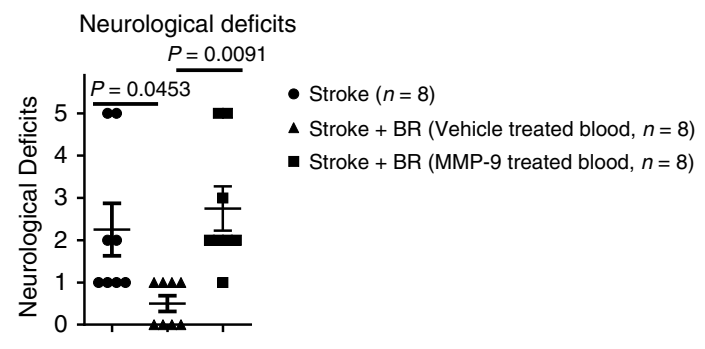

Fig. 8 MMP-9 diminished the therapeutic effects of the blood replacement in stroke mice. a Experimental design. Mice (8-month-old males) underwent tMCAO for $60 \mathrm{~min}$. The occlusion and reperfusion were confirmed by a laser speckle imager (LSI). Mice were randomized into three groups: the first group is the stroke group received $\mathrm{MCCAO}$, the second group is the blood replacement (BR) group receiving $250 \mu$ of blood with vehicle and blood withdrawal, and the third group is the BR group receiving $250 \mu$ l of blood treated with activated MMP-9 $(5 \mu \mathrm{g} \mathrm{ml}-1)$ and blood withdrawal. b Quantification of infarct volumes in the cortex, striatum, and total hemisphere. MMP-9-treated blood did not significantly reduce the infarct volume. Stroke group (circles, $n=6$ ), stroke with vehicle-treated BR group (triangles, $n=8$ ), and stroke with MMP-9-treated BR group (squares, $n=6$ ). c Representative TTC-stained coronal brain sections used for infarction analyses. d Neurological deficits were not significantly improved in the BR group with MMP-9-treated blood. Stroke group (circles, $n=8$ ), stroke with vehicle-treated BR group (triangles, $n=8$ ), and stroke with MMP-9-treated BR group (squares, $n=8$ ). Data were presented as means \pm SEM. One-way ANOVA followed by post hoc Tukey's multiple comparison tests. Source data are provided as a Source Data file.

However, the results demonstrated that plasma transfusion did not protect stroke outcomes as observed in whole-BR (Supplementary Fig. 7). Plasma transfusion did not change cellular components in blood as compared to whole blood obtained from stroke mice donors (Fig. 4). The data also suggest that the beneficial effects of the BR therapy is not simply due to a dilution of blood in recipients. Transfusion of $500 \mu \mathrm{l}$ of whole blood or plasma is considered less than $20 \%$ of total blood volume into a mouse. However, reduced neutrophil numbers (Fig. 4b) and the levels of MMP-9 (Fig. 7b) by the BR therapy are far more than $20 \%$. In addition, the data from proinflammatory cytokine and chemokine panel (Fig. 7) also suggest that BR therapy does not simply cause a dilution effect in the blood of stroke mice. Therefore, we believe that BR therapy might reduce a cascade response to a stroke that may be able to provide such a profound protection in stroke brains.

It is important to identify key factors responsible for the positive effects of a blood transfusion, because they may lead to the development of cellular and molecule interventions with a better efficacy. However, the role of specific cell types in producing ischemic brain damage remains a controversial topic and the mechanisms of how inflammatory cells and their mediators are involved in stroke-induced neuro-inflammation are still not fully understood. In patients with ischemic stroke, the number of circulating neutrophils rise within the first few hours of stroke onset $^{23}$. This increase is associated with stroke severity ${ }^{24}$, infarct volume $^{25}$, and worse functional outcomes ${ }^{26,27}$. Kleinschnitz et al. ${ }^{28}$ has demonstrated that transfer of $\mathrm{CD} 3^{+} \mathrm{T}$ cells is detrimental for cerebral ischemia and $\mathrm{T}$ cells critically contribute to cerebral ischemia; however, the role of regulatory $\mathrm{T}$ cells has been a controversial concept in the stroke field for a decade ${ }^{29}$. B cells are documented protective in acute stroke ${ }^{30}$. Although we determined that the BR therapy substantially decreased neutrophils in blood (Fig. 4c, d) and brains (Fig. 6) of stroke mice, we demonstrated that the removal of blood from recipient stroke mice is essential to develop this therapeutic strategy (Supplementary Fig. 4), which may help release of inflammatory cells from blood. We argue that the BR therapy could change leukocyte trafficking and migration into brains when the BBB is closed. For example, macrophages/monocytes were not significantly changed in the peripheral blood (Fig. 4c, e) but BR therapy substantially decreased macrophages/monocytes in stroke brains; B cells were significantly increased in the peripheral blood by the BR therapy (Fig. 4i, j) but very few B cells were detected in ischemic brains. It is important to determine specific roles of white blood cell subsets by BR therapy administration following a stroke to optimize therapeutic strategies in the future.

It has been confirmed that MMP-9 is a key proteinase associated with $\mathrm{BBB}$ leakage, extracellular matrix degradation, and evolution of cerebral ischemia ${ }^{7}$. Opening of the BBB is transient following a stroke ${ }^{3}$. Compromised BBB integrity allows blood solutes and inflammatory cells to flow into the brain causing adverse stroke outcomes such as brain edema and neuronal death. The shorter time the BBB remains open, the less influx of 
deleterious materials enters into the brain. We did observe that the $\mathrm{BBB}$ is protected following the BR therapy in stroke mice (Fig. 1e, f). Decreased level of MMP-9 in the periphery and CNS (Fig. 7) could be one important mechanism in closing the BBB by BR therapy for stroke. We have recently demonstrated a mitochondrial mechanism in BBB opening following a stroke ${ }^{31-33}$. Due to the analyses of physiological parameters demonstrated that $\mathrm{BR}$ therapy did not change $\mathrm{PO} 2, \mathrm{PCO}$, and glucose level in recipient stroke mice (Supplementary Table 1), our data do not support the possibility that BR therapy rescues ischemic brains by changing the physiological parameters. However, it is possible that blood provides nutrition and protective factors that can help cerebrovascular endothelial cells restore mitochondrial function and seal BBB tight junctions following a stroke.

It is known that inflammatory cytokines and chemokines play a harmful role in acute stroke ${ }^{34}$. We observed significantly higher levels of proinflammatory cytokines IL-1 $\beta$, IL- 6 , and TNF- $\alpha$ in plasma of stroke mice and the BR therapy decreased the levels of these cytokines in plasma (Fig. 5). As active MMP-9 cleaves a variety of chemokines ${ }^{8}$ and cytokines ${ }^{9-11}$, and triggers signaling through various transmembrane proteins ${ }^{35}$, the BR therapy might reduce the cascade inflammatory responses in stroke through reduced levels of MMP-9 in blood (Fig. 7). It is noted that chemokine CXCL1, a neutrophil-activating protein, is substantially increased in stroke and significantly reduced by the BR therapy at an early time point post stroke. The cellular source of CXCL1 is not clear; however, the elevated CXCL1 may explain that neutrophils are the first responders that react to acute ischemia ${ }^{36}$ and CXCL1 may account for the rise of neutrophils in the blood and brains following a stroke.

Others have demonstrated that knockout of MMP-9 or inhibition of MMP-9 can be of therapeutic importance in ischemic stroke $^{37}$. It has been shown that MMP-9 inhibitors DP-b9938, KBR7785 ${ }^{39}, \mathrm{SB}-3 \mathrm{CT} \mathrm{T}^{40}$, and BB- $94^{37}$ protect stroke outcomes. Even though BR therapy profoundly protects stroke outcomes, addition of MMP-9 to the blood diminishes the protective effect of the BR therapy and substantially worsens stroke outcomes (Fig. 8). These data elucidate an MMP-9-involved mechanism in the BR therapy in stroke and also suggest the importance of measuring the level of MMP-9 in donor blood for transfusion. The dose of MMP-9 administrated is $1.25 \mu \mathrm{g} 30 \mathrm{~g} \mathrm{~g}^{-1}$ mouse, relative to $500 \mathrm{ng} \mathrm{ml}^{-1}$ MMP-9 in blood of recipient mice. This level corresponds to doubled levels of MMP-9 in blood following a stroke (Fig. 7a). It is reported that higher plasma levels of pro-MMP-9 early in stroke are correlated with larger infarct volumes ${ }^{41}$. We did observe that longer occlusion causes worse stroke outcomes and more proinflammatory responses in early stroke. Permanent stroke causes more profound inflammatory responses and higher levels of MMP-9 in blood. Therefore, blood obtained from permanent stroke mice donors worsened stroke outcomes and caused a high mortality in stroke mice (Supplementary Fig. 5).

Sex differences exist in response to stroke ${ }^{42-45}$ and age is another factor that affects stroke outcomes ${ }^{46}$. It is not clear whether blood obtained from different sexes and ages contributes to different outcomes in stroke. We used blood obtained from relatively young mice (3 6 months old) and transfused the whole blood into older stroke mice (8 12 months old) in the study. Our ongoing study will further address the role of blood obtained from a wide range of ages of both males and females.

Currently, blood-based therapies are emerging as treatments to combat aging and fight neurodegenerative diseases ${ }^{47}$. It is not likely that the complex pathological changes following a stroke can be treated by any known, single medication. The proposed BR therapy offers a strategy that targets the pathological systemic responses to stroke. The results of this study could lead to a breakthrough in stroke therapy, because this innovative therapeutic strategy may reduce the mortality of stroke patients and improve stroke outcomes. These results can provide a foundation for the future use of BR therapy in clinical trials for improved treatment of strokes.

\section{Methods}

Study approval. The ARRIVE guidelines were followed and Institutional Animal Care and Use Committee at West Virginia University (WVU) approved criteria for procedures prior to experimentation.

Animals: We used male 8 12 months old C57/BL6J mice (above $30 \mathrm{~g}$; Jackson's Laboratory, ME) for recipients and male 3 6 months old C57/BL6J mice for blood donors. We used 333 mice for the study. We numbered the animals and allocated them into groups using a simple randomization of excel-generated random numbers. To avoid biases, we also assured that different treatments were performed on the same day.

Murine focal cerebral ischemia model. We anesthetized mice with $4-5 \%$ isoflurane and maintained anesthesia such that animals did not respond to toe pinch with $1-2 \%$ isoflurane via face mask in oxygen-enriched air. We induced focal cerebral ischemia by occlusion of the right middle cerebral artery for $90 \mathrm{~min}$ with a 6.0 monofilament suture (Doccol, Sharon, MA) and maintained a rectal body temperature of $37 \pm 0.5^{\circ} \mathrm{C}$ throughout the surgery. We confirmed a successful occlusion by changes of regional cerebral blood flow using Laser Speckle Imager (Moor Instruments, UK) and applied a local analgesia (bupivacaine $1 \mathrm{mg} \mathrm{kg}^{-1}$, subcutaneously (s.c.)) after stroke surgeries.

Preparation of blood for transfusion. We prepared fresh blood obtained from naive donors or stroke mice via cardiac puncture while animals were under deep anesthesia. We collected blood in a syringe containing citrate-phosphate-dextrose (CPD) buffer ( $150 \mu \mathrm{lml}^{-1}$ blood) and rapidly mixed with anti-coagulated CPD buffer for transfusion. Recombinant mouse MMP-9 protein (R\&D, USA) was activated in buffer ( $50 \mathrm{mM}$ Tris, $10 \mathrm{mM} \mathrm{CaCl}_{2}, 150 \mathrm{mM} \mathrm{NaCl}, 0.05 \%$ Brij-35, pH 7.5) with $1 \mathrm{mM}$-aminophenylmercuric acetate for $2 \mathrm{~h}$ then added in fresh prepared blood $\left(5 \mu \mathrm{g} \mathrm{ml}^{-1}\right)$ for transfusion.

Blood replacement. We conducted all procedures under anesthesia (4-5\% isoflurane induction and $1-2 \%$ isoflurane maintenance). We placed a catheter (prewashed with CPD buffer and dried $26 \mathrm{G}$, Monoject ${ }^{\mathrm{TM}}$, Covidien, Italy) into left femoral vein for blood transfusion and another catheter (pre-washed with heparin and dried) was placed into right femoral artery for the blood withdrawal. We connected a microinjection pump (Genie Touch ${ }^{\mathrm{TM}}$, Lucca Technologies) with the catheter in the femoral vein with a speed of $20 \mu \mathrm{min}^{-1}$ for blood transfusion. To withdraw blood, we attached a syringe to the catheter in femoral artery. When the procedure was completed, we removed the catheters and blotted the incision with sterilized cotton swabs until cessation of bleeding. We then closed the incisions with sutures and applied a local analgesia (bupivacaine $1 \mathrm{mg} \mathrm{kg}^{-1}$, s.c.) following the BR surgeries.

BBB permeability in vivo. We used Evan's blue extravasation assay to evaluate BBB permeability in mice. We administered Evan's blue intravenously through tai vein 30 minutes prior to euthanization. We transcardially perfused animals with saline and sectioned brains with a $2 \mathrm{~mm}$ coronal brain matrix. We weighed hemisphere samples and homogenized samples with $400 \mu \mathrm{L}$ phosphate-buffered solution (PBS), and then precipitated with $50 \%$ trichloroacetic acid (Sigma, CA) overnight. We centrifuged all samples were $300 \times g$ for $30 \mathrm{~min}$ to separate out the brain tissue in pellet prior to measuring. We quantified Evans blue in the brain by absorption at $610 \mathrm{~nm}$ with a plate reader (BioTek, Winooski, VT). Final results were quantified as Evans blue microgram/gram brain tissue.

Exclusion criteria. We excluded animals according to the criteria below: (1) regional cerebral blood flow decreases $<70 \%$ during occlusion as detected by Laser Speckle Imager; (2) surgical procedures last more than $30 \mathrm{~min}$; (3) no neurological deficits at $3 \mathrm{~h}$ post-tMCAO; (4) invisible infarction in the MCA territory by TTC staining; (5) postmortem examination shows subarachnoid hemorrhage; and (6) substantial ambient temperature changes in the facility. Animals that died prior to the planned time of assessments were postmortem examined for subarachnoid hemorrhage and the mortality was recorded. In this study, five mice were excluded: three mice (one mouse in sham BR control group and two mice in BR group of blood obtained from stroke mice) because of subarachnoid hemorrhage, two mice (prior to group randomization), because the Laser Speckle Imager did not detect $70 \%$ reduction of $\mathrm{CBF}$ after MCAO. The experimenters were blinded to the treatments for data collection and analysis.

Brain histology. We cut brains in $2 \mathrm{~mm}$ brain coronal matrix and stained resulting sections with $2 \%$ TTC (Sigma, Saint Louis, MO) in PBS at $37^{\circ} \mathrm{C}$ for $30 \mathrm{~min}$. We photographed brains using a photo scanner and fixed the tissues in $10 \%$ formalin for 1 week. We used four sections of seen images for data qualification. We 
analyzed infarct volumes within the cortex, striatum, and total hemisphere using NIH Image J software.

We embedded fixed brain sections in paraffin and cut coronal slices $(10 \mu \mathrm{m})$ through the brain hippocampus area. We performed Cresyl Violet (Sigma, Saint Louis, MO), H\&E (Sigma, Saint Louis, MO), TUNEL staining (TUNEL Assay Kit HRP-DAB, Abcam, Cambridge, MA), and Fluoro-Jade C staining (Sigma, Saint Louis, MO) on slides following the manufacturers' instructions. We took bright field images for Cresyl Violet, H\&E, TUNEL staining, and fluorescent field images for Fuoro Jade C staining through a slide scanner (Olympus VS120, Japan) at the Microscope Imaging Facility at WVU.

Neurological deficits. We measured neurological functioning on a $0-5$ scale, where $0=$ no neurological dysfunction; $1=$ failure to extend contralateral forelimb when lifted by tail; 2 = circling to the contralateral side; $3=$ falling to the contralateral side; $4=$ nonspontaneous walk or in a comatose state; $5=$ death.

Flow cytometry. We lysed red blood cells in blood by red blood cell lysis buffer (eBioscience) and isolated leukocytes in brains by $37-70 \%$ Percoll (GE Healthcare) density gradient centrifugation. We counted cell numbers by a Coulter counter (Thermo Fisher). Cells were washed with buffer (PBS with $0.5 \%$ bovine serum abumin and $0.02 \%$ sodium azide) for three times and stained with antibodies listed in Supplementary Table 2. We used BD FACS LSRFortesa (12 fluorochromes, three-laser system, BD Biosciences) with FACS Diva version 8.0 software (BD Biosciences) to determine the phenotypes of leukocytes. We excluded dead cells by propidium iodide (Sigma, $20 \mathrm{\mu g} \mathrm{ml}^{-1}$ in PBS) positive staining and analyzed the data using Flowjo version 10 software (TreeStar).

Electrochemiluminescence assay for cytokines and chemokines. We used an electrochemiluminescence assay to detect a proinflammatory panel by multiplex kits obtained from Meso Scale Discovery (Rockville, MD). The kits included individual assay for quantification of IFN- $\gamma$, IL-1 $\beta$, IL-2, IL-4, IL-5, IL-6, IL-10, IL12 , and TNF- $\alpha$, and the chemokine CXCL1. We followed the manufacturer's protocol for evaluation of plasma samples. We read the results on MSD multi-array imaging platform. We carried out the data analyses using the MSD discovery workbench software.

ELISA for detection of MMP-9. We obtained murine MMP-9 detection kits from R\&D System and analyzed levels of total MMP-9 in plasma and brains followed the manufacturer's instructions. We recorded the results by a Biotek Synergy H1 Hybrid plate reader (wavelength $=450 \mathrm{~nm}$ ).

Statistical analyses. We conducted statistical analyses with PRISM 7 software (GraphPad Software, La Jolla, CA). One-way analysis of variance followed by post hoc test was used for the analysis of data above two groups. The Brown-Forsythe test was performed for equal population variances among multiple comparisons. Student's $t$-test was used for the analysis of data between two groups. G*Power v.3.1.9.2 was used to decide power for the animal study. Fisher's exact test was used to determine the difference of mortality between groups. All measurements were taken from distinct samples. Statistical significance was set at $p<0.05$ (two-sided).

Reporting summary. Further information on research design is available in the Nature Research Reporting Summary linked to this article.

\section{Data availability}

Source data are provided as a Source Data file with this paper. The data that support the findings of this study are available from the corresponding author (X.R.) upon reasonable request. Source data are provided with this paper.

Received: 2 April 2019; Accepted: 22 July 2020;

Published online: 25 August 2020

\section{References}

1. Feigin, V. L., Norrving, B. \& Mensah, G. A. Global burden of stroke. Circ. Res. 120, 439-448 (2017).

2. Dirnagl, U. et al. Stroke-induced immunodepression: experimental evidence and clinical relevance. Stroke 38, 770-773 (2007)

3. Hone, A. E. et al. Biphasic blood-brain barrier openings after stroke. Neurol. Disord. Stroke Int. 1, 1-4 (2018).

4. Sarvari, S., Moakedi, F., Hone, E., Simpkins, J. W. \& Ren, X. Mechanisms in blood-brain barrier opening and metabolism-challenged cerebrovascular ischemia with emphasis on ischemic stroke. Metab. Brain Dis. 35, 851-868 (2020).

5. Simpkins, A. N., Dias, C. \& Leigh, R., National Institutes of Health Natural History of Stroke Investigators. Identification of reversible disruption of the human blood-brain barrier following acute ischemia. Stroke 47, 2405-2408 (2016).

6. Lakhan, S. E., Kirchgessner, A. \& Hofer, M. Inflammatory mechanisms in ischemic stroke: therapeutic approaches. J. Transl. Med. 7, 97 (2009).

7. del Zoppo, G. J. The neurovascular unit, matrix proteases, and innate inflammation. Ann. N. Y. Acad. Sci. 1207, 46-49 (2010).

8. Vafadari, B., Salamian, A. \& Kaczmarek, L. MMP-9 in translation: from molecule to brain physiology, pathology, and therapy. J. neurochemistry 139, 91-114 (2016)

9. Scholz, J. \& Woolf, C. J. The neuropathic pain triad: neurons, immune cells and glia. Nat. Neurosci. 10, 1361-1368 (2007).

10. Kawasaki, Y. et al. Distinct roles of matrix metalloproteases in the early- and late-phase development of neuropathic pain. Nat. Med. 14, 331-336 (2008).

11. Roghani, M. et al. Metalloprotease-disintegrin MDC9: intracellular maturation and catalytic activity. J. Biol. Chem. 274, 3531-3540 (1999).

12. Mizuma, A. \& Yenari, M. A. Anti-inflammatory targets for the treatment of reperfusion injury in stroke. Front. Neurol. 8, 467 (2017).

13. Rayasam, A. et al. Immune responses in stroke: how the immune system contributes to damage and healing after stroke and how this knowledge could be translated to better cures? Immunology 154, 363-376 (2018).

14. Chintakuntlawar, A. V. \& Chodosh, J. Chemokine CXCL1/KC and its receptor CXCR2 are responsible for neutrophil chemotaxis in adenoviral keratitis. J. Interferon Cytokine Res. 29, 657-666 (2009).

15. Yabluchanskiy, A., Ma, Y., Iyer, R. P., Hall, M. E. \& Lindsey, M. L. Matrix metalloproteinase-9: many shades of function in cardiovascular disease. Physiology (Bethesda) 28, 391-403 (2013).

16. Heo, J. H. et al. Matrix metalloproteinases increase very early during experimental focal cerebral ischemia. J. Cereb. Blood Flow. Metab. 19, 624-633 (1999).

17. Kelly, P. J. et al. Oxidative stress and matrix metalloproteinase-9 in acute ischemic stroke: the Biomarker Evaluation for Antioxidant Therapies in Stroke (BEAT-Stroke) study. Stroke 39, 100-104 (2008).

18. Tang, Y. et al. Gene expression in blood changes rapidly in neutrophils and monocytes after ischemic stroke in humans: a microarray study. J. Cereb. Blood Flow. Metab. 26, 1089-1102 (2006).

19. Stamova, B. et al. Gene expression profiling of blood for the prediction of ischemic stroke. Stroke 41, 2171-2177 (2010).

20. Dane, K. \& Chaturvedi, S. Beyond plasma exchange: novel therapies for thrombotic thrombocytopenic purpura. Hematology Am. Soc. Hematol. Educ. Program 2018, 539-547 (2018).

21. Sluiter, W., Oomens, L. W., Brand, A. \& Van Furth, R. Determination of blood volume in the mouse with 51chromium-labelled erythrocytes. J. Immunol. Methods 73, 221-225 (1984).

22. Middeldorp, J. et al. Preclinical assessment of young blood plasma for Alzheimer disease. JAMA Neurol. 73, 1325-1333 (2016).

23. Ross, A. M. et al. Evidence of the peripheral inflammatory response in patients with transient ischemic attack. J. Stroke Cerebrovasc. Dis. 16, 203-207 (2007).

24. Kim, J. et al. Different prognostic value of white blood cell subtypes in patients with acute cerebral infarction. Atherosclerosis 222, 464-467 (2012).

25. Buck, B. H. et al. Early neutrophilia is associated with volume of ischemic tissue in acute stroke. Stroke 39, 355-360 (2008).

26. Kumar, A. D. et al. Leukocytosis in patients with neurologic deterioration after acute ischemic stroke is associated with poor outcomes. J. Stroke Cerebrovasc. Dis. 22, e111-e117 (2013).

27. Akopov, S. E., Simonian, N. A. \& Grigorian, G. S. Dynamics of polymorphonuclear leukocyte accumulation in acute cerebral infarction and their correlation with brain tissue damage. Stroke 27, 1739-1743 (1996).

28. Kleinschnitz, C. et al. Early detrimental T-cell effects in experimental cerebral ischemia are neither related to adaptive immunity nor thrombus formation. Blood 115, 3835-3842 (2010).

29. Liesz, A., Hu, X., Kleinschnitz, C. \& Offner, H. Functional role of regulatory lymphocytes in stroke: facts and controversies. Stroke 46, 1422-1430 (2015).

30. Ren, X. et al. Regulatory B cells limit CNS inflammation and neurologic deficits in murine experimental stroke. J. Neurosci. 31, 8556-8563 (2011).

31. Doll, D. N. et al. Mitochondrial crisis in cerebrovascular endothelial cells opens the blood-brain barrier. Stroke 46, 1681-1689 (2015).

32. $\mathrm{Hu}, \mathrm{H}$. et al. MiR-34a interacts with cytochrome $\mathrm{c}$ and shapes stroke outcomes. Sci. Rep. 10, 3233 (2020).

33. $\mathrm{Hu}, \mathrm{H}$. et al. Mitochondrial impairment in cerebrovascular endothelial cells is involved in the correlation between body temperature and stroke severity Aging Dis. 7, 14-27 (2016).

34. Romi, F., Helgeland, G. \& Gilhus, N. E. Serum levels of matrix metalloproteinases: implications in clinical neurology. Eur. Neurol. 67, 121-128 (2012).

35. De Paiva, C. S. et al. Cleavage of functional IL-2 receptor alpha chain (CD25) from murine corneal and conjunctival epithelia by MMP-9. J. Inflamm. 6, 31 (2009). 
36. Jin, R., Yang, G. \& Li, G. Inflammatory mechanisms in ischemic stroke: role of inflammatory cells. J. Leukoc. Biol. 87, 779-789 (2010).

37. Asahi, M. et al. Role for matrix metalloproteinase 9 after focal cerebral ischemia: effects of gene knockout and enzyme inhibition with BB-94. J. Cereb. Blood Flow. Metab. 20, 1681-1689 (2000).

38. Diener, H. C. et al. DP-b99, a membrane-activated metal ion chelator, as neuroprotective therapy in ischemic stroke. Stroke 39, 1774-1778 (2008).

39. Jiang, X., Namura, S. \& Nagata, I. Matrix metalloproteinase inhibitor KBR7785 attenuates brain damage resulting from permanent focal cerebral ischemia in mice. Neurosci. Lett. 305, 41-44 (2001).

40. $\mathrm{Gu}, \mathrm{Z}$. et al. A highly specific inhibitor of matrix metalloproteinase- 9 rescues laminin from proteolysis and neurons from apoptosis in transient focal cerebral ischemia. J. Neurosci. 25, 6401-6408 (2005).

41. Park, K. P. et al. Plasma and brain matrix metalloproteinase- 9 after acute focal cerebral ischemia in rats. Stroke 40, 2836-2842 (2009).

42. Liu, M., Dziennis, S., Hurn, P. D. \& Alkayed, N. J. Mechanisms of genderlinked ischemic brain injury. Restor. Neurol. Neurosci. 27, 163-179 (2009).

43. Cheng, J. \& Hurn, P. D. Sex shapes experimental ischemic brain injury. Steroids 75, 754-759 (2010).

44. Herson, P. S., Koerner, I. P. \& Hurn, P. D. Sex, sex steroids, and brain injury. Semin. Reprod. Med. 27, 229-239 (2009).

45. Liu, M., Kelley, M. H., Herson, P. S. \& Hurn, P. D. Neuroprotection of sex steroids. Minerva Endocrinol. 35, 127-143 (2010).

46. Sieber, M. W. et al. Age-specific transcriptional response to stroke. Neurobiol. Aging 35, 1744-1754 (2014).

47. Wyss-Coray, T. Ageing, neurodegeneration and brain rejuvenation. Nature 539, 180-186 (2016).

\section{Acknowledgements}

We thank Emily Hone for performing ELISA to detect the levels of MMP-2 and MMP-9. We thank Deborah Corbin for performing TUNEL staining and acquiring images. The study is supported by AHA SDG (16SDG31170008 to X.R.), NSF (1916894 to X.R.), WVCTSI (NIH/NIGMS U54GM104942 to X.R.), WVU Bridge Funding Grant (to X.R.), and NIH CoBRE (P20 GM109098 to J.W.S.). The Olympus VS120 Slide Scanner is supported by NIH (P20GM103434). The Fortessa is supported by NIH S10 grant (OD016165)

\section{Author contributions}

X.R. designed the study, performed the experiments, and wrote the manuscript. H.H. performed the experiments. I.F. performed the experiments. J.W.S. designed the study and edited the manuscript.

\section{Competing interests}

The authors declare no competing interests.

\section{Additional information}

Supplementary information is available for this paper at https://doi.org/10.1038/s41467020-17930-x.

Correspondence and requests for materials should be addressed to X.R. or J.W.S.

Peer review information Nature Communications thanks John Lukens and other anonymous, reviewers for their contributions to the peer review of this work.

Reprints and permission information is available at http://www.nature.com/reprints

Publisher's note Springer Nature remains neutral with regard to jurisdictional claims in published maps and institutional affiliations.

(c) (i) Open Access This article is licensed under a Creative Commons Attribution 4.0 International License, which permits use, sharing, adaptation, distribution and reproduction in any medium or format, as long as you give appropriate credit to the original author(s) and the source, provide a link to the Creative Commons license, and indicate if changes were made. The images or other third party material in this article are included in the article's Creative Commons license, unless indicated otherwise in a credit line to the material. If material is not included in the article's Creative Commons license and your intended use is not permitted by statutory regulation or exceeds the permitted use, you will need to obtain permission directly from the copyright holder. To view a copy of this license, visit http://creativecommons.org/ licenses/by/4.0/.

(C) The Author(s) 2020, corrected publication 2021 